\title{
Gas-to-Liquids (GTL) Plant Optimization Using Enhanced Synthesis Gas Reforming Technology
}

\author{
Izuwa Nkemakolam Chinedu, Obah Boniface, Ekwueme Stanley Toochukwu, \\ Obibuike Ubanozie Julian, Kerunwa Anthony*, Ohia Nnaemeka Princewill, Odo Jude Emeka \\ Department of Petroleum Engineering, Federal University of Technology, Owerri, Nigeria \\ Email address: \\ ncizuwa@yahoo.com (I. N. Chinedu), stanleyekwueme@yahoo.com(E. S. Toochukwu), anthonykerunwa@rocketmail.com(K. Anthony) \\ ${ }^{*}$ Corresponding author
}

To cite this article:

Izuwa Nkemakolam Chinedu, Obah Boniface, Ekwueme Stanley Toochukwu, Obibuike Ubanozie Julian, Kerunwa Anthony, Ohia Nnaemeka Princewill, Odo Jude Emeka. Gas-to-Liquids (GTL) Plant Optimization Using Enhanced Synthesis Gas Reforming Technology. Petroleum Science and Engineering. Vol. 3, No. 2, 2019, pp. 94-102. doi: 10.11648/j.pse.20190302.18

Received: October 21, 2019; Accepted: November 23, 2019; Published: December 13, 2019

\begin{abstract}
This paper evaluates method for optimisation of GTL plant using Steam/ $\mathrm{CO}_{2}$ reforming for syngas generation. Extensive modelling of GTL plant has been done. Two cases were considered during the simulation of the GTL plant. The first case was the use of oxygen gas as the feed reactant gas using an auto-thermal reformer for the production of synthesis gas. The alternative case which is the proposed method uses $\mathrm{CO}_{2}$ in lieu of oxygen for the production of synthesis gas. $\mathrm{CO}_{2}$ method was chosen because of its cheap availability and the ability to be recycled from purge gas and reused reducing pollution. Honeywell's Unisim software was used for the simulation and the Peng Robinson equation of state was chosen as the fluid property package. The simulation was done unit by unit and integration of all units was made. The synthesis gas unit was simulated in Unisim as a conversion type reactor using two separate reactors while three equilibrium reactors were used to control the water gas shift reaction to maintain favourable $\mathrm{H}_{2} / \mathrm{CO}$ ratio. The FT reactor was modelled as a multi-tubular bed reactor and simulated as a plug flow reactor (PFR) in Unisim using heterogeneous catalytic reaction type. Technical and economic performances were analyzed for both methods. The technical analyses revealed that the proposed steam $/ \mathrm{CO}_{2}$ method gave a $\mathrm{H}_{2} / \mathrm{CO}$ ratio of 2.17 as against the 2.21 gotten for the ATR. Furthermore, the carbon efficiency of the two methods revealed $77.68 \%$ and $92.17 \%$ for base case and the proposed methods respectively showing that the proposed case has higher efficiency. The liquid yields show that the proposed method has a liquid yield of 5730b/d over the $5430 \mathrm{~b} / \mathrm{d}$ gotten from the base case representing an increase in product yield of $5.5 \%$.
\end{abstract}

Keywords: Gas-to-liquid, Optimization, Synthetic Gas, Heterogeneous, Performances, Natural Gas, Catalytic Reaction

\section{Introduction}

Recently, natural gas witnessed tremendous growth in utility as a result of technology advancement especially in developed economies. Equally, natural gas offers clean energy needed to meet global environmental requirement. The reason for this is clear - as a fossil fuel, it is abundant in nature and as a green fuel, it leaves very low carbon footprint when burnt making it an environmentally friendly fuel. Natural gas resources were not monetized early like crude oil due to poor infrastructure and technology giving rise to indiscriminate gas flaring [1]. The global transition in natural gas utilization was fuelled by the emergence of natural gas utilization technologies [2]. Among these technologies gasto-liquids technology stood out as the one most fungible in today's value chain. This is because it yields transport liquids high in demand, transported with conventional crude oil product pipelines and used in their liquid state without reconversion processes. It has been proven that GTL liquids show superiority over conventional crude oil product in terms of performance and pollution characteristics [3, 4].

Research has shown that among the various steps present in the GTL system, the syngas generation step is the most capital intensive [5]. This is because of its high energy consumption, cost of construction and complexity of configuration as an additional unit. In traditional GTL syngas generation, autothermal reforming has been proven and 
selected as the best for syngas generation in terms of efficiency and economy [6-9]. Thus, many commercial GTL plants utilize this method for syngas generation. Because it requires oxygen as its feedstock, there is need for external supply of oxygen. This is gotten from separating oxygen in the air through the use of an air separation unit (ASU) configured with the system [10]. The volume of oxygen required is dependent on the capacity of the plant. For commercial plants, large volume of oxygen is usually required and this significantly results to high capital cost of the syngas process, which adds to the overall capital cost of the GTL system. For some plants, syngas generation takes about $40 \%$ of the capital cost of the GTL system [11]. In optimizing the plant, it is necessary to provide an alternative approach in the autothermal reforming unit that will reduce the volume of oxygen intake or replace the oxygen fuel with some other fuel that is cheap and readily available. A new method is provided in this work. The method uses $\mathrm{CO}_{2}$ instead of $\mathrm{O}_{2}$ in a steam $/ \mathrm{CO}_{2}$ reforming process as alternative to the autothermal reforming. Thus, the $\mathrm{CO}_{2}$ in the raw natural gas is utilized. This method reduces the capital cost of the syngas generation and the overall capital cost of the GTL plant is reduced due to the following reasons [12]: No need for use of the Air separation unit (ASU) for $\mathrm{O}_{2}$ generation, no need for use of $\mathrm{CO}_{2}$ removal unit in the treatment plant, no need for use of $\mathrm{H}_{2}$ conditioning unit for syngas, because syngas generated using $\mathrm{CO}_{2}$ instead of $\mathrm{O}_{2}$ is pure.

\section{Problem Identification}

The problems identified in GTL plant operations that prompted this research work are given below

1. GTL plant processes have high capital cost. Most of these costs come from the synthesis gas unit, the type of synthesis gas technology used in the production of synthesis gas affects the overall cost of the GTL operation. Many investors shy away from GTL because of this high capital cost.

2. Conventional GTL technologies using steam methane reformer or autothermal reformers are net generators of $\mathrm{CO}_{2}$ which causes severe environmental pollution.

3. The required $\mathrm{H}_{2} / \mathrm{CO}$ ratio for optimal Fisher Tropsch Liquid reaction is 2 . This conversion ratio has to be provided by the synthesis gas reformer. If this ratio is not provided or maintained by the synthesis gas reformer, the reaction in the FT unit for liquid transport fuel will not be optimal and efficiency of the unit will not be maximized. It is necessary to choose the synthesis gas reformer that will economically produce synthesis gas whose ratio is close to or equal to 2 in order to maximize liquids in the Fisher Trospch reaction unit.

Given a GTL process with certain units and feedstock specifications, it is required to develop a techno-economic analysis of the process and to reduce its cost and enhance its energy efficiency. This can be achieved by considering the following: 1) Identification, simulation and analyses of the base case problem. 2) Development, simulation and analysis of alternative method retrofitted to reduce cost and enhance energy efficiency. 3) Recognition and implementation of optimisation methods for both cases if necessary.4) Identification of the optimal working conditions of the two methods in terms of the objective functions which are cost and energy efficiency.

In bid to address the problems listed above, two cases shall be considered, the base case and the alternative case after which technical performance analyses shall be carried out for the two processes to determine its strengths and weaknesses.

For this work, the factor that determine distinction in operations foreach case is the choice of technology and approach for the production of the synthesis gas. Thus, of the primary stages in the GTL process, the synthesis gas stage defines and distinguishes the base case from the alternative case.

The present work's main cases considered are summarized below.

\subsection{Base Case (Case 1)}

In this case, we designed a GTL process plant and its operation for the production of premium GTL Transport fuel using Autothermal reforming method as the method for the synthesis gas production. The synthesis gas here is the precursor to the actual Fischer Tropsch reaction. The Autothermal reformer (ATR) uses oxygen from air separation unit (ASU) as one of the reactants. Other reactants includes steam and the pre-treated natural gas.

\subsection{Alternative Case (Case 2)}

For case 2, we designed a GTL process plant that will minimize cost and enhance performance and less pollution. In this work, we propose a method that is $\mathrm{CO}_{2}$ reductive, this method utilizes the inherent $\mathrm{CO}_{2}$ in the natural gas, consumes the $\mathrm{CO}_{2}$ that is produced in the reaction phases and also uses the $\mathrm{CO}_{2}$ that is in the effluent stream of the GTL plant for the production of synthesis gas in the syngas unit using steam $/ \mathrm{CO}_{2}$ reforming technology. Furthermore $\mathrm{CO}_{2}$ is supplied externally from the market to get the required amount necessary for the synthesis gas production.

\section{Methodology}

The processes involved in GTL plants operations are:1) The natural gas pre-treatment units. 2) The synthesis gas unit3) The Fisher Tropsch unit and 4) The product upgrading unit

These four main units in the GTL plants have their peculiar operation, processes, considerations and objectives. A full GTL plant process is an integration of these units and processes for a common goal. Each unit is peculiar and distinct from the other and is important to the overall integrated steam. 


\subsection{The Natural Gas Pre-Treatment Unit}

This unit sees that the natural gas from the flare point is pre-treated to remove impurities or reduce them to acceptable levels for the actual GTL process. The actual GTL plant operations begin from the synthesis gas unit. For this work, the choice of pre-treatment varies for each case considered. Because of the different principles involved in the reforming of the two cases considered, their pre-treatment also differs. This difference affects the choice of their technologies and process applications. For optimal treating-complex design, process selection for the individual units must be made on the basis of an integrated approach that consider interactions

\section{between units}

For the ATR reformer, the aim of the pretreatment is to remove all impurities or at least reduce it to a level that can be tolerated by the catalyst and equipment in the subsequent syngas units. For these the acid gases, Nitrogen, Mercaptans and other impurities are removed from the natural gas. Many approach to achieve this exist but the selected approach for this work is use of amine systems to sweeten the sour flare gas. The diagram below gives a schematic description of the process used for the acid gas removal from the raw flare gas for the ATR syngas process method.

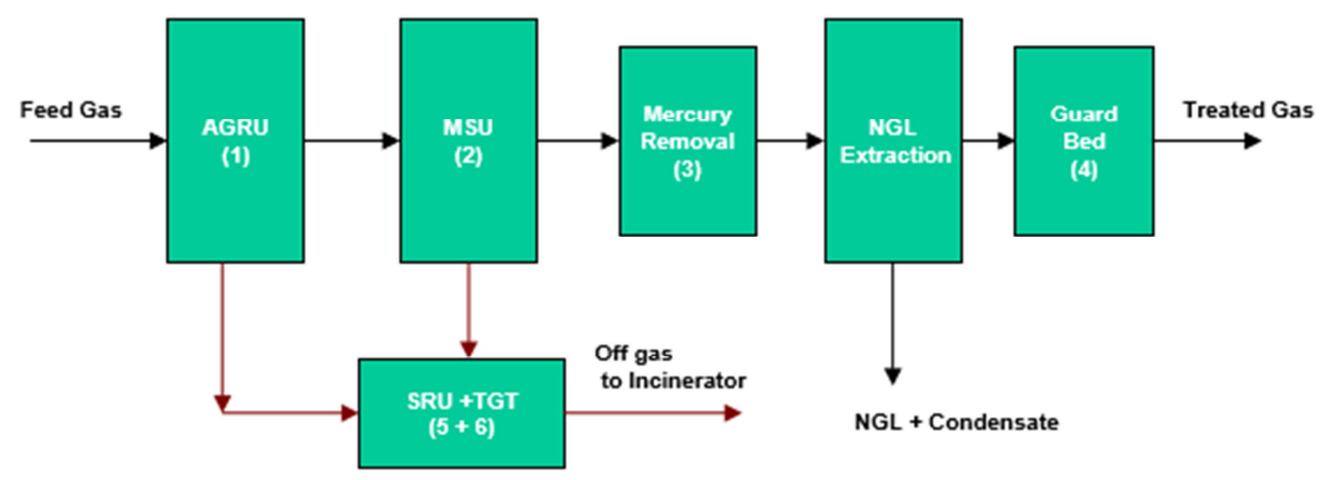

Figure 1. Typical block flow scheme of sour natural gas treating unit [13].

The acid gas removal unit (AGRU) removes $\mathrm{H}_{2} \mathrm{~S}$ and some of the mercaptans. The molecular sieve unit (MSU) removes the bulk of the mercaptans and dries the gas to specification for the NGL recovery unit. Mercury is removed prior to NGL extraction. The final step being the guard bed ensures that stringent sulphur component specification of the downstream process is met.

Although, GTL processes do not require full removal of the acid gases, removal of acid gases must be done to a level that can be tolerated by the GTL plant. $\mathrm{CO}_{2}$ of $0.5-1 \%$ mole can be tolerated while the specification of sulphur level must be less than $0.1 \mathrm{ppm}$ weight.

The steam $/ \mathrm{CO}_{2}$ reforming for the alternative method requires a new method for the pretreatment of the raw flare gas other than the one suggested above. This is because the $\mathrm{CO}_{2}$ in the natural gas will not be removed so that it can take part in the reaction. For this only the $\mathrm{H}_{2} \mathrm{~S}$ and the other sulphur components needs be removed. Thus the pretreatment for the steam $/ \mathrm{CO}_{2}$ method is mainly a desulphurization of the raw flare natural gas. We proposed a method to achieve the desulphurization which consist of passing the raw natural gas feed at about 572 to $752^{\circ} \mathrm{F}$ over cobalt molybdenum catalyst in the presence of hydrogen to convert the organic sulphur containing compounds to hydrogen sulphide according to the equation

$$
\mathrm{NG}+\mathrm{S}+\mathrm{H}_{2} \rightarrow \mathrm{H}_{2} \mathrm{~S}+\mathrm{NG}
$$

This is then followed by adsorption of the hydrogen sulphide on zinc oxide in a guard chamber to form zinc sulphide according to the reaction below in equation 2 . This reaction reduces the sulphur level in the natural gas to less than $0.1 \mathrm{ppm}$ wt. which is the level that can be tolerated by downstream GTL equipment.

$$
\mathrm{NG}+\mathrm{H}_{2} \mathrm{~S}+\mathrm{ZnO} \rightarrow \mathrm{ZnS}+\mathrm{H}_{2} \mathrm{O}+\mathrm{NG}
$$

The pretreated natural gas either in the base case or in the alternative case is feed to the synthesis gas unit.

Sample of the pretreated natural gas composition is given in the table 2 .

Table 1. Mole composition of the raw natural gas from the flare stack.

\begin{tabular}{ll}
\hline Component & Mole Composition (Mol \%) \\
\hline Methane & 80.15 \\
Ethane & 5.13 \\
Propane & 3.75 \\
N-butane & 2.54 \\
I-Pentane & 1.58 \\
N-Pentane & 1.24 \\
Hexane & 0.76 \\
Nitrogen & 1.24 \\
$\mathrm{CO}_{2}$ & 1.88 \\
Hydrogen sulphide & 1.73 \\
Total & 100 \\
\hline
\end{tabular}

Table 2. Mole composition of natural gas after pretreatment and processing (pre-reformer feed composition).

\begin{tabular}{ll}
\hline Composition & Mole Fraction \% \\
\hline Methane & 95.5 \\
Ethane & 3 \\
Propane & 0.5 \\
N-Butane & 0.4 \\
I-Butane & 0.2 \\
Nitrogen & 0.4 \\
Total & 100 \\
\hline
\end{tabular}


When the raw natural gas has undergone pretreatment and desulphurization, then three main steps remain available for the conversion of the gas to liquids

\subsection{The Synthesis Gas Unit}

The synthesis gas unit includes the following sub-sections, a pre-reformer, heating unit, and a reformer (ATR for base case and steam $/ \mathrm{CO}_{2}$ reformer for alternative case):

1. The pre-reformer cracks heavier hydrocarbons in the pre-treated natural gas stream before being sent to the reformer. Here all the hydrocarbons that are heavier than methane are converted to synthesis gas and methane according to equation 3. In addition, the methanation and shift reactions (equations 4 and 5) are assumed to be in equilibrium.

$$
\begin{gathered}
\text { forn } \geq 2, \mathrm{C}_{n} \mathrm{H}_{m}+\mathrm{H}_{2} \mathrm{O} \rightarrow\left(n+\frac{m}{2}\right) \mathrm{H}_{2}+n \mathrm{CO} \\
\mathrm{CO}+3 \mathrm{H}_{2} \leftrightarrow \mathrm{CH}_{4}+\mathrm{H}_{2} \mathrm{O} \\
\mathrm{CO}+\mathrm{H}_{2} \mathrm{O} \leftrightarrow \mathrm{CO}_{2}+\mathrm{H}_{2}
\end{gathered}
$$

The inlet composition and temperature of the inlet streams determine the exit temperature of the adiabatic pre-reformer. The exit temperature is between 212 and $572^{\circ} \mathrm{F}$ lower than the desired ATR inlet temperature, which means that a heater is needed.

2. The heating unit supplies the required energy for

a. Preheating Fresh natural gas and Recycle hydrocarbons from FT reactor, (i.e. the pre-reformer feed) to $851^{\circ} \mathrm{F}$

b. Superheated process steam (pre-reformer feed) and superheated steam for driving the turbine compressor in the oxygen plant and the much smaller recycled tail gas compressor.

c. Preheating the outlet gas from the pre-reformer to $948.15^{\circ} \mathrm{F}$ (optimized value)

d. Preheating oxygen or $\mathrm{CO} 2$ as the case may be to $473.15^{\circ} \mathrm{F}$

The combustible components in the purge stream plus some fresh natural gas supplies the needed fuel to be used in the fired heater. We assumeda $98 \%$ efficiency for the fuel combustion.

3. The reformer converts methane in the stream from the heating unit to syngas by reacting it with steam and oxygen $/ \mathrm{CO}_{2}$. It is modeled as an adiabatic equilibrium reactor

For the base case ATR, the following reactions is seen:

Oxidation of Methane:

$$
\mathrm{CH}_{4}+1.5 \mathrm{O}_{2} \leftrightarrow \mathrm{CO}+2 \mathrm{H}_{2} \mathrm{O}
$$

Steam Reforming of Methane:

$$
\mathrm{CH}_{4}+\mathrm{H}_{2} \mathrm{O} \leftrightarrow \mathrm{CO}+3 \mathrm{H}_{2}
$$

Water Shift reaction:

$$
\mathrm{CO}+\mathrm{H}_{2} \mathrm{O} \leftrightarrow \mathrm{CO}_{2}+\mathrm{H}_{2}
$$

The ASU supplies the needed oxygen which is sent to the ATR. For GTL applications with a cobalt-based FischerTropsch reactor, a typical $\mathrm{H}_{2}$ to $\mathrm{CO}$ ratio in the fresh syngas is about 2, though the exact value is obtained during optimisation of the process.

The hot syngas leaving the ATR is cooled to ambient temperature in order to separate out waterbefore it goes to the $\mathrm{CO}_{2}$ capture unit.

For the steam $/ \mathrm{CO}_{2}$ method the following reactionsare seen in the reformer

Steam Reforming of Methane

$$
\mathrm{CH}_{4}+\mathrm{H}_{2} \mathrm{O} \rightarrow \mathrm{CO}+3 \mathrm{H}_{2}
$$

Dry Reforming of Methane

$$
\mathrm{CH}_{4}+\mathrm{CO}_{2} \rightarrow 2 \mathrm{CO}+2 \mathrm{H}_{2}
$$

Water Shift reaction:

$$
\mathrm{CO}+\mathrm{H}_{2} \mathrm{O} \leftrightarrow \mathrm{CO}_{2}+\mathrm{H}_{2}
$$

\subsection{Fischer-Tropsch Unit}

The synthesis gas is sent to the Fischer-Tropsch (FT) unit where there is high exothermic reaction. The FT reactor is assumed to be isothermal having a temperature of $410^{\circ} \mathrm{F}$. The reactions are typically written in the following form:

$$
n \mathrm{CO}+2 n \mathrm{H}_{2} \leftrightarrow\left(-\mathrm{CH}_{2}-\right)_{n}+n \mathrm{H}_{2} \mathrm{O}
$$

In addition, the production of methane is unavoidable

$$
\mathrm{CO}+3 \mathrm{H}_{2} \leftrightarrow \mathrm{CH}_{4}+\mathrm{H}_{2} \mathrm{O}
$$

In simulation of the reaction, the reaction rates for $\mathrm{CO}$ consumption and $\mathrm{CH}_{4}$ formation as proposed by Iglesia et al was used, alongside the carbon mass balance as given by the ASF distribution model. The Iglesias's reaction rates on cobalt catalyst are valid at the following conditions:

1. Temperature of $408^{\circ} \mathrm{F}$ to $4100^{\circ} \mathrm{F}$

2. Pressure of 100 to $3000 \mathrm{kPa}$,

3. Synthesis gas ratio of $\mathrm{H}_{2} / \mathrm{CO}=1$ to 10

The Iglesias' reaction rate on cobalt catalyst is for $\mathrm{CO}$ consumption and $\mathrm{CH}_{4}$ formation are given below

$$
\begin{array}{r}
r_{C H_{4}}=\frac{k_{1} P_{2} P C O^{0.05}}{1+\left(K_{1} P C O\right)} \\
r_{C O}=\frac{k_{2} P_{2}{ }^{0.6} P C O^{0.65}}{1+\left(K_{1} P C O\right)}
\end{array}
$$

The values for $\mathrm{A}, \mathrm{E}, \mathrm{n}$ and the various component exponents of equations 12 and 13 for use in Unisim are given in table 3 . 
Table 3. Parameters used for kinetic rate expression in Unisim for modeling of the FT reactions.

\begin{tabular}{|c|c|c|c|c|c|c|}
\hline \multirow{2}{*}{ Reactions } & \multirow{2}{*}{$\mathbf{A}$} & \multirow{2}{*}{$\mathbf{E}$} & \multirow{2}{*}{ Exponent $\mathrm{PH}_{2}$} & \multicolumn{2}{|c|}{ Exponent PCO } & \multirow[b]{2}{*}{$\mathbf{n}$} \\
\hline & & & & Numerator & Denominator & \\
\hline \multicolumn{7}{|l|}{$r_{\mathrm{CH}_{4}}$} \\
\hline $\mathrm{k} 1$ & $8.8 * 10-6$ & 37326 & 1 & 0.05 & - & - \\
\hline \multicolumn{7}{|l|}{$r_{C O}$} \\
\hline $\mathrm{k} 2$ & $1.6 * 10-5$ & 37326 & 0.6 & 0.65 & - & - \\
\hline $\mathrm{K} 2$ & $1.096 * 10-12$ & -68401.5 & - & - & 1 & 1 \\
\hline
\end{tabular}

The simulated reactor is a multi-tubular fixed bed (MTFB) reactor. The Fischer-Tropsch synthesis was modelled as given by the ASF distribution. Paraffins were the hydrocarbons considered in this work and, $\alpha$ was assumed to be 0.9. Allthe components lower than carbon number 21 was modelled as individual units, while the components with carbon number from 21-30 was lumped in a component designated $\mathrm{C}_{21}+$. The stoichiometric coefficients were calculated from Equations given below:

$$
\begin{gathered}
\mathrm{CO}+\mathrm{UH}_{2} \rightarrow r_{F T 1} C_{1}+r_{F T 2} C_{2}+---r_{F T N-1} C_{N-1}+r_{F T N, \infty} C_{N, \infty}+H_{2} O \\
X_{[N, \infty]}=N+\frac{\alpha}{1-\alpha}=30
\end{gathered}
$$

The overall FT reaction was modeled in Unisim as one reaction, and written as

This means that $\mathrm{C}_{[\mathrm{N}, \infty]}=\mathrm{C}_{30}$ represents $\sum_{\mathrm{N}=21}^{\infty} \mathrm{C}_{\mathrm{N}}$

Where $\mathrm{N}=21$

The direct equation of reaction used for the FT reaction in this work is given below.

$$
\begin{array}{r}
\mathrm{CO}+2.1 \mathrm{H}_{2} \rightarrow 0.01 \mathrm{CH} 3+0.009 \mathrm{C} 2 \mathrm{H} 6+0.008 \mathrm{C} 3 \mathrm{H} 8+0.007 \mathrm{C} 4 \mathrm{H} 10+0.007 \mathrm{C} 5 \mathrm{H} 12+0.006 \mathrm{C} 6 \mathrm{H} 14+0.005 \mathrm{C} 7 \mathrm{H} 16+ \\
0.004 \mathrm{C} 8 \mathrm{H} 18+0.004 \mathrm{C} 9 \mathrm{H} 20+0.003 \mathrm{C} 10 \mathrm{H} 22+0.003 \mathrm{C} 11 \mathrm{H} 24+0.003 \mathrm{C} 12 \mathrm{H} 26+0.003 \mathrm{C} 13 \mathrm{H} 28+0.002 \mathrm{C} 14 \mathrm{H} 30+ \\
0.002 \mathrm{C} 15 \mathrm{H} 32+0.002 \mathrm{C} 16 \mathrm{H} 34+0.002 \mathrm{C} 17 \mathrm{H} 36+0.002 \mathrm{C} 18 \mathrm{H} 38+0.001 \mathrm{C} 19 \mathrm{H} 40+0.012 \mathrm{C} 20 \mathrm{H} 42+\mathrm{C} 21+\mathrm{H} 2 \mathrm{O}(18)
\end{array}
$$

\subsection{Operational Constraints}

The following constraints is considered for optimization:

(1) Molar ratioH $\mathrm{H}_{2} \mathrm{O} / \mathrm{C} \geq 0.3$ in feed to syngas unit. This is to avoid soot formation in the ATR.

(2) Reformer exit temperature is $1030^{\circ} \mathrm{C}$. This is to ensure soot-free operation.

(3) Inlet temperature to the reformer $675^{\circ} \mathrm{C}$. This is a material constraint.

(4) The purge ratio is optimally around $2 \%$.

\subsection{Simulation of the GTL Plant}

\subsubsection{Simulation of ATR Reformer (Base Case)}

The design specifications and requirements are discussed in this section on the basis of feed, product and operating conditions of the units.

The GTL plant was modelled in steady state condition using Honeywell's Unisim R380. In setting up the model, Peng-Robinson was chosen as the fluid property package and all hydrocarbon components with $C_{4}^{+}$were added as n-type hydrocarbons and $\mathrm{C}_{21} \rightarrow \infty$ was modelled as $\mathrm{C}_{30}$ due to similarities in their properties. The reactions were added in sets for the three main units operations, Pre-reformer, ATR and FT-reactor respectively.

The simulation for the main GTL plant is described thus; first natural gas is heated from $104^{\circ} \mathrm{F}$ to $850^{\circ} \mathrm{F}$ by a heater. This is the common range for pre-reformer. The initial temperature of the steam was set at $485^{\circ} \mathrm{F}$. The heated natural gas and steam is sent to the pre-reformer. The pre-reformer was modeled as a conversion reaction while its water gas shift reaction was modelled as an equilibrium reactor. The pre-reformer temperature and pressure was set at $986^{\circ} \mathrm{F}$ and 435 psia respectively. The outlet gas from the pre-reformer was sent to the ATR. The ATR was modelled as a conversion reactor while its water gas shift was modeled as equilibrium reaction in a distinct equilibrium reactors. Because of the exothermic nature of the ATR reaction, its upper temperature was set at a limit of $1886^{\circ} \mathrm{F}$ in order to avoid soot formation.

Heat exchanger which was connected at the downstream end of the ATR enabled the temperature of the synthesis gas to be brought down to $100.4^{\circ} \mathrm{F}$. This reduction in temperature enables the steam generated in the ATR to be converted to water which can be separated out before the subsequent FT reaction, thus causing a reduction in the volume flow and hence the reactor size. But $100.4^{\circ} \mathrm{F}$ is too low a temperature for the low temperature Fischer Tropsch (LTFT) process which runs at $392-464^{\circ} \mathrm{F}$. A heater was included in the model to heat up the Fischer Tropsch Reactor (FTR) inlet to $410^{\circ} \mathrm{F}$.

The FTR was modelled as a plug flow reactor (PFR) as this flow pattern mainlylook like a multi tubular fixed bed (MTFB) reactor. The starting volume was chosen to be $1000 \mathrm{~m}^{3}$. The FT reaction set was defined as kinetic and it included both the FT reaction and the methanation reaction. The stoichiometric coefficients for the FT reactions are modelled based on the ASF-distribution and the kinetics was 
implemented by the use of Iglesias rate of reaction.

The products of the MTFB reactor are gaseous and liquid products, gas and liquid products are separated inside the reactor by gravity- gas leaving at the top and liquid products trickling down and exiting the bottom. The gaseous products are cooled by heat exchanging with water to $100.4^{\circ} \mathrm{F}\left(38^{\circ} \mathrm{C}\right)$ before entering the 3-way separator together with the liquid products. This was done to separate out water that left the reactor as steam. This will eliminate unnecessary recycling and water being sent to product upgrading.

In the 3-way separator more water is removed, liquid products are sent to upgrading unit and the remaining gases is split in a purge and a recycle stream.

The overall view of the GTL process schematics done on Unisim R380 software is given in the figure below

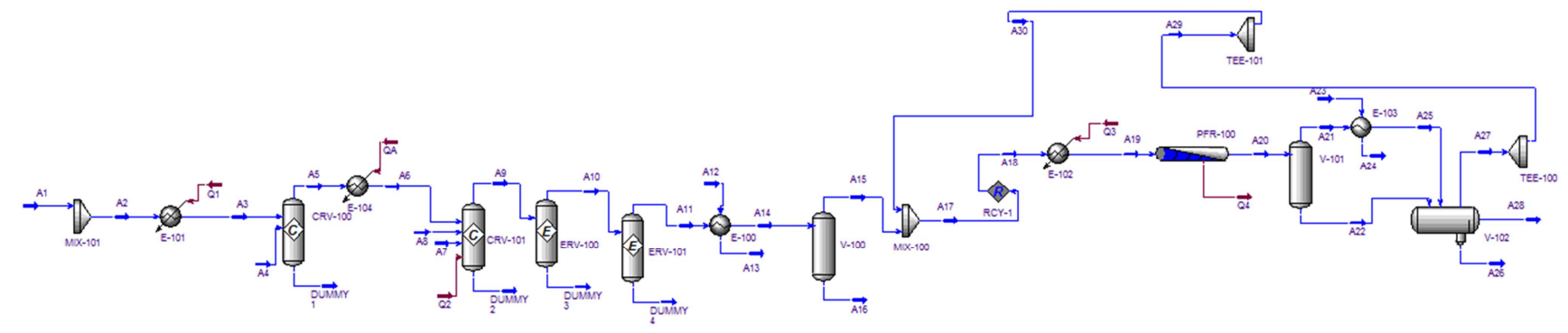

Figure 2. Complete process layout of the ATR GTL plant design in Unisim.

From the figure above, it can be seen that the first two conversion reactors modelled the pre-reformer and ATR reformer respectively while the last two equilibrium reactors modelled the water gas shift reaction from the pre-reformer and the reformer respectively.

The synthesis gas unit is very important to the operation because it is the deciding factor in the success of the FT reaction. The equilibrium reactors in the synthesis gas unit is necessary to achieve favourable $\mathrm{H}_{2} / \mathrm{CO}$ ratio required for the FT unit. The figure below shows a distinct layout of the simulated synthesis gas unit.

\subsubsection{Simulation of the Steam/CO $\mathrm{O}_{2}$ Reformer (Alternative Case)}

For the pre-reformer unit the desulphurized natural gas is pre-heated to $851^{\circ} \mathrm{F}$ just as in the case of the ATR. The heated gas is sent to the pre-reformer. Steam enters the prereformer at $410^{\circ} \mathrm{F}$. The pre-reformer just as in the case of the ATR was modelled as a conversion reactor while the water gas shift reaction was modelled as an equilibrium reaction.

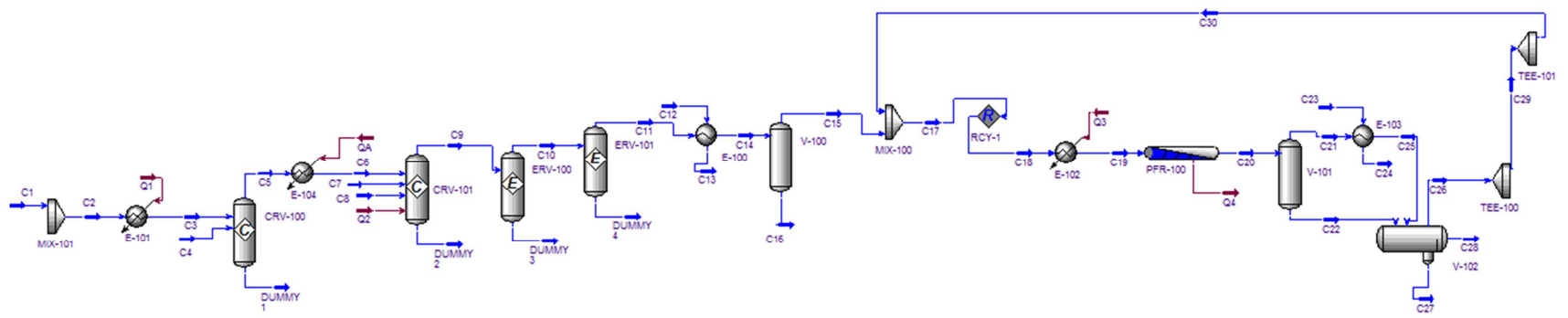

Figure 3. The Unisim simulation of the steam $/ \mathrm{CO}_{2}$ showing the synthesis gas and FT stages.

\section{Result and Discussions}

The results give the technical performance analyses of the GTL plant for the base case and the proposed case. In the technical performance analyses, we evaluated the parametres of the specific design and operation of the GTL processing using the following.

1. $\mathrm{H}_{2} / \mathrm{CO}$ ratio

2. Thermal and carbon efficiencies

3. Methane conversion/carbon conversion

4. $\mathrm{CO}_{2}$ production/emission

5. GTL Product Yields

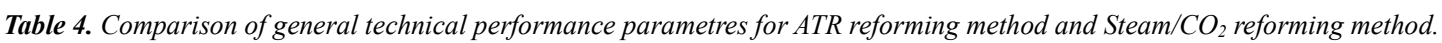

\begin{tabular}{lll}
\hline Parameter & Base Case (ATR) & Proposed method (Steam/CO) \\
\hline $\mathrm{H}_{2}$ /CO ratio at FT inlet & 2.21 & 2.17 \\
$\mathrm{O}_{2}$ molar flow at reformer inlet (MMscfd) & 50.19 & 50.19 \\
Steam molar flow at pre-reformer inlet (MMscfd) & 90.35 & 90.35 \\
Steam molar flow at reformer inlet (MMscfd) & 90.35 & 90.35 \\
Carbon efficiency (\%) & 77.68 & 92.17 \\
Thermal efficiency (\%) & 65.16 & 68.76 \\
Steam/carbon ratio at the pre-reformer & 0.58 & 0.58 \\
Steam/carbon ratio at the reformer & 0.58 & 0.87 \\
Methane conversion (\%) & 76.06 & 84 \\
\hline
\end{tabular}




\begin{tabular}{lll}
\hline Parameter & Base Case (ATR) & Proposed method $\left(\mathbf{S t e a m} / \mathbf{C O}_{2}\right)$ \\
\hline unreacted methane (MMscfd) & 11.43 & 7.64 \\
Unreacted methane (\%) & 23.94 & 16 \\
Unreacted carbon (MMscfd) & 15.23 & 8.44 \\
Unreacted carbon (\%) & 28.91 & 16.01 \\
$\mathrm{CO}_{2}$ emission (MMscfd) & 22.02 & 5.04 \\
Diesel production (b/d) & 3025 & 3120 \\
Gasoline production (b/d) & 1380 & 14225 \\
Kerosene production (b/d) & 1025 & 1185 \\
Total Product Yield (b/d) & 5430 & 5730 \\
\hline
\end{tabular}

\section{1. $\mathrm{H}_{2} / \mathrm{CO}$ Ratio}

From table 4 above, the Steam $/ \mathrm{CO}_{2}$ reforming has a $\mathrm{H}_{2} / \mathrm{CO}$ ratio of 2.17 while that of ATR reforming GTL plant is 2.21. The best $\mathrm{H}_{2} / \mathrm{CO}$ ratio for an efficient FT reaction is 2.0. Thus, the $\mathrm{H}_{2} / \mathrm{CO}$ ratio of 2.17 from the proposed method is better than the $\mathrm{H}_{2} / \mathrm{CO}$ ratio of 2.21 from the ATR. A $\mathrm{H}_{2} /$ COratio closer to 2 is better because it favours the production of lighter end component (transport) liquids at the Fisher Tropsch plant. The $\mathrm{H}_{2} / \mathrm{CO}$ ratio synthesis gas reformer of the CompactGTL facility at Kazakhstan during its operation was found to be 2.14 which is very close to the value of 2.17 in the proposed method. The GTL operation at Kazakhstan gives us an experimental value to validate the accuracy of our GTL simulation using the Unisim simulation software. The error margin is $1.4 \%$ which is within acceptable limits for process plant operations.

\section{Thermal and carbon efficiencies}

From table 4 above, the carbon efficiency of the ATR reforming GTL plant $77.68 \%$ while that of the steam $/ \mathrm{CO}_{2}$ reforming GTL plant is $92.17 \%$; the thermal efficiencyof the ATR reforming GTL plantis65.16\% while that of the steam $/ \mathrm{CO}_{2}$ reforming GTL plant is $68.76 \%$. Considering both the carbon and the thermal efficiencies of the two methods, it is seen that the steam $/ \mathrm{CO}_{2}$ reforming process which is the proposed method has higher carbon and thermal efficiencies than the base ATR reforming method which is the base case. Thus higher carbon and thermal efficiencies justifies the use of steam $/ \mathrm{CO}_{2}$ reforming than the ATR (Table 4). The difference in carbon and thermal efficiencies of the steam $/ \mathrm{CO}_{2}$ reforming and the ATR reforming is $14.49 \%$ and $3.6 \%$ respectively. This shows that steam $/ \mathrm{CO}_{2}$ reforming is better than ATR reforming.

\section{Methane Conversion/Carbon Conversion}

In the syngas plant, the performance of the plant is also measured by the percentage and volume of unreacted methane at the exit of the reactors. An efficient GTL synthesis gas option is the configuration that achieves the best conversion of the methane into synthesis gas. From table 4 above, the percentage conversion of methane for the ATR reformer GTL plant is $76.06 \%$ unreacted methane produced at the end of the reforming is 11.43 MMscfd (23.94\%). The carbon conversion is $71.09 \%$ while the total unreacted carbon in the reformer exit stream is $15.24 \mathrm{MMscfd}$ (28.91\%). The methane conversion for the steam $/ \mathrm{CO}_{2}$ reforming of the GTL plant is $84 \%$ while the unreacted methane in the product stream is $7.64 \mathrm{MMscfd}(16 \%)$. The carbon conversion is also $83.99 \%$ while the unreacted carbon is 8.44 MMscfd
(16.01\%). The results shows that the Steam/ $\mathrm{CO}_{2}$ plant has greater conversion of the feedstock to intermediate synthesis gas products for the GTL operation than the ATR reformer GTL plant.

\section{4. $\mathrm{CO}_{2}$ Production/Emission}

From table 4 above, the percentage $\mathrm{CO}_{2}$ volume of the gas stream at the exit of the ATR reformer is $7.06 \%$ of the ATR reformer exit stream corresponding to a molar volume of 22.02 MMscfd $(1096.8 \mathrm{Kgmol} / \mathrm{hr})$. The $\mathrm{CO}_{2}$ content of the product stream corresponding to the pollution characteristics of the steam $/ \mathrm{CO}_{2}$ reformer is $5.04 \mathrm{MMscfd}$. From these values, it can be seen that the $\mathrm{CO}_{2}$ emissionfrom the steam $/ \mathrm{CO}_{2}$ reforming GTL plant is much smaller than that produced in the ATR reforming GTL plant. This is because the steam $/ \mathrm{CO}_{2}$ reforming GTL plant was configured and equipped to capture and re-use $\mathrm{CO}_{2}$ generated in the GTL processes thereby drastically reducing the overall carbon emission. The Lower pollution characteristics in terms of carbon emission gotten from the use of steam $/ \mathrm{CO}_{2}$ reforming method over the ATR reforming GTL plant shows that the use of steam $/ \mathrm{CO}_{2}$ reforming is more environmentally friendly than the ATR method.

5. GTL Plant Product Yields

The GTL simulation yield is summarized in the table below.

Table 5. GTL plant product yield for ATR syngas method.

\begin{tabular}{lll}
\hline \multirow{2}{*}{ Component } & Volume (b/d) & \\
\cline { 2 - 3 } & ATR & Steam/ $\mathbf{C O}_{\mathbf{2}}$ \\
\hline Gasoline & 3025 & 3120 \\
Kerosene & 1380 & 1425 \\
Diesel & 1025 & 1185 \\
Total & 5430 & 5730 \\
\hline
\end{tabular}

From table 5 above, the product yield from the steam $/ \mathrm{CO}_{2}$ reforming is $5730 \mathrm{~b} / \mathrm{d}$ while that of the ATR method is $5430 \mathrm{~b} / \mathrm{d}$. For a rule of thumb, the liquid product yield for GTL plant is 1 barrel for 10,000 scf of pre-treated natural gas feedstream. From this calculation, the feedstream corresponds to a conventional production of $5000 \mathrm{~b} / \mathrm{d}$. Both the ATR reforming method and the steam $/ \mathrm{CO}_{2}$ reforming method gave high product yields. When compared with the expected yield from the rule of thumb, the product yield from the steam $/ \mathrm{CO}_{2}$ reforming method represents a $14.6 \%$ increase while the product yield from the ATR plant represents an $8.6 \%$ increase. Thus, the steam $/ \mathrm{CO}_{2}$ has more product yield and is preferred as a choice over the ATR reforming GTL plant method. 
Figure 4 and 5 show the temperature and mole fracture inside the Fisher Trospch reactor (FTR) during synthesis gas conversion. The figures reveal the distribution of temperature and the mole fraction of products in the FT reactor. The FT reactor is influenced by the temperature of the stream coming from the reformer. The temperature of the FT reactor affects the mole fraction of components produced in the FT reactor.

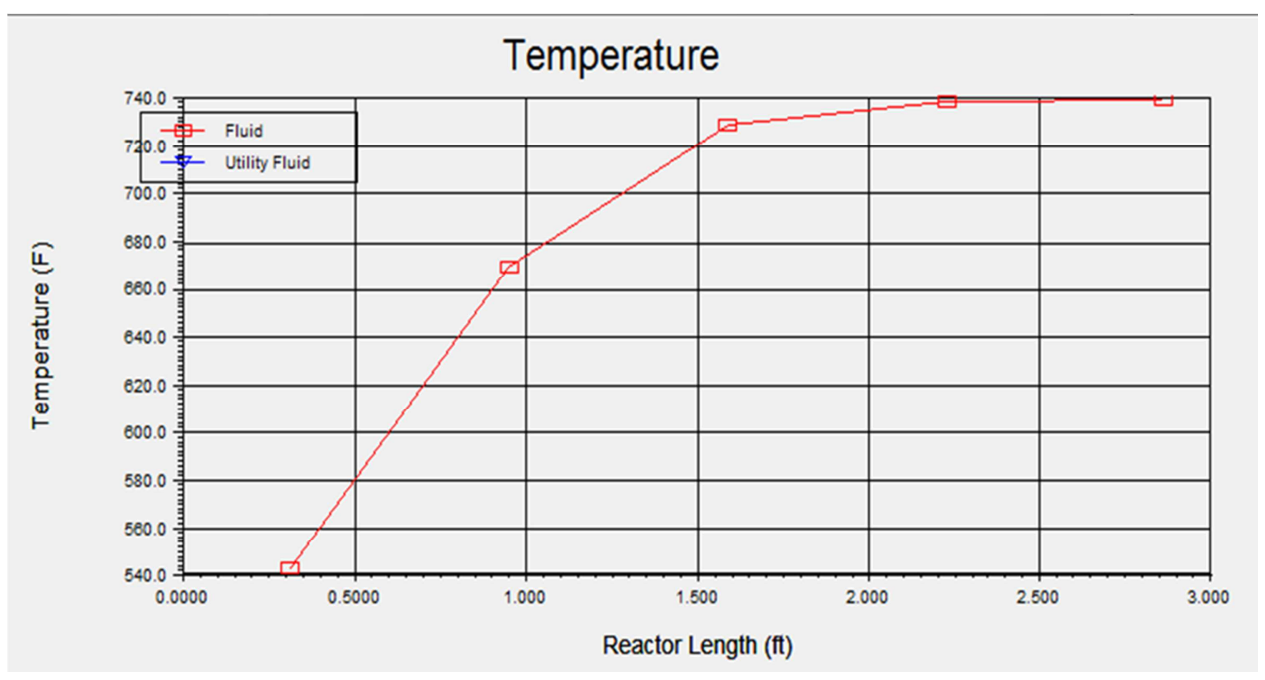

Figure 4. Graph of temperature and reaction length in the FTR.

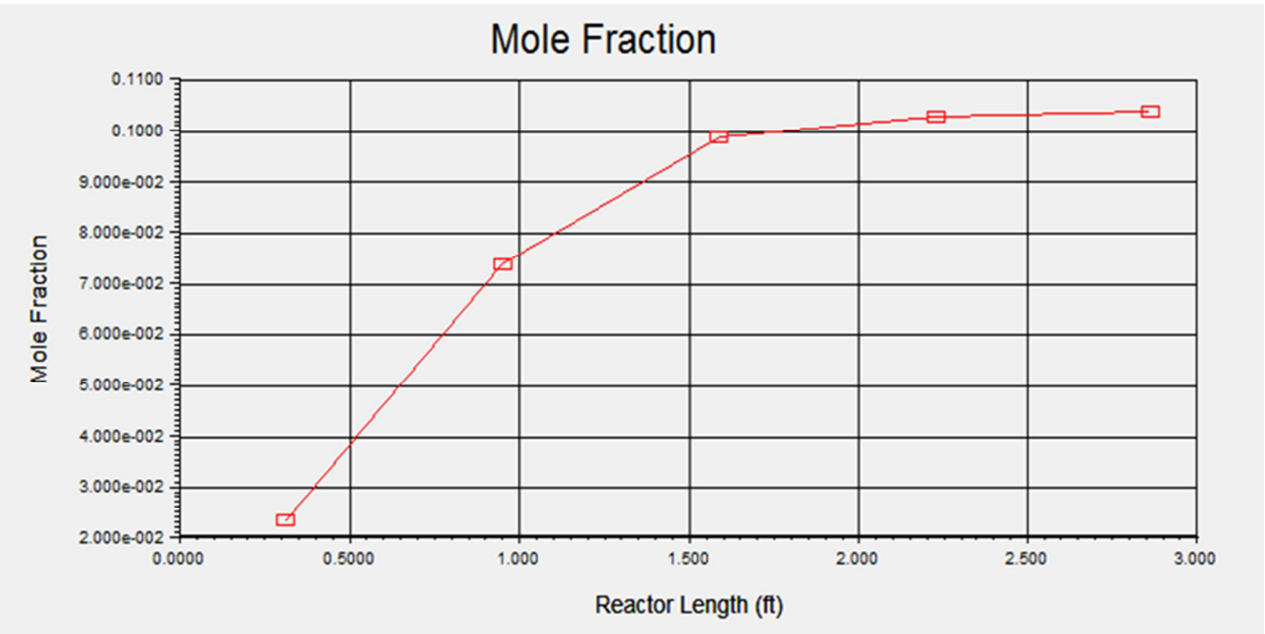

Figure 5. Mole fraction of paraffins in FTR.

\section{Conclusion}

In this work, steam/ $/ \mathrm{CO}_{2}$ reforming process was used to optimize the production of GTL products from natural gas. The use of steam $/ \mathrm{CO}_{2}$ improved the performance of the syngas unit through increased production of synthesis gas. It also reduced the emission of $\mathrm{CO}_{2}$. Results from this study showed lower emission of $\mathrm{CO}_{2}$ compared to the industrial standard - the use of steam $/ \mathrm{O}_{2}$ (autothermal reforming process) in the syngas unit for synthesis gas production.

The technical performance revealed that the proposed method (alternative case) is more technically justifiable for use in the GTL project than the base case method in terms of carbon and thermal efficiency, pollution characteristics, $\mathrm{H}_{2} / \mathrm{CO}$ ratio, carbon and thermal efficiencies, product yield (table 4 and 5). Hence, the proposed GTL method is recommended for GTL plant during GTL plant configuration and development for an optimal GTL operation, especially for stranded flare gas utilization and monetisation using GTL process schemes.

\section{Nomenclature}

ASF: Anderson-Schultz-Floury

ASU: Air separation Unit

GTC: Gas-to-Chemicals

PFR: Plug Flow Reactor

ATR: Autothermal Reforming

AGRU: Acid Gas Removal Unit

MSU: Molecular sieve Unit

NGL: Natural gas liquids

NG: Natural Gas

LTFT: Low temperature Fischer Tropsch

FT: Fischer Tropsch

FTR: Fischer Tropsch Reactor 


\section{References}

[1] Izuwa, N. C. (2017). Improving Natural Gas Distribution and Management in Nigeria. International Journal of Scientific \& Engineering Research, IJSER, Volume 8, Issue 7, pp 330-344.

[2] Eluagu, C., Anyadiegwu, C. I. C, Obah, B. O (2018). Evaluation of Performance Optimisation of Modular Gas Technology (MGT) System for Monetisation of Associated Stranded Gas in the Niger Delta. International Journal of Engineering Sciences \& Research Technology.

[3] Ekejiuba, A. I. B., (2017). Real-Time Monetization of the Flare Associated Stranded Natural Gas in Nigeria: Quantitative Analysis and Qualitative Values. The International Journal of Science \& Technology, Vol. 5 Issue 8, pp. 154.

[4] Onwukwe S. (2009). Gas-to-Liquid technology: Prospect for natural gas utilization in Nigeria: Journal of Natural Gas Science and Engineering.

[5] Balogu, O. M. Onyekonwu, M. O. (2009). Economic Viability of Gas-to-Liquids in Nigeria. Paper Presented at the Annual SPE international Technical Conference and Exhibition, Abuja, Nigeria.

[6] Knutsen K. T. (2013). Modelling and optimization of a Gasto-Liquid plant. Master's degree thesis, Department of Chemical Engineering, Norwegian University of science and technology.

[7] Christiansen Lars J Rostrup-Nielsen Jens. (2011). Concepts in Syngas Manufacture. Imperial College Press.

[8] Spath, P. L. \& Dayton, D. C. (2003). Preliminary screening technical and economic assessment of synthesis gas to fuels and chemicals with emphasis on the potential for biomassderived syngas. Technical report, National Renewable Energy Laboratory.

[9] Wilhelm, D. J Simbeck, D. R et al. (2001). Syngas production for gas-to-liquids applications: technologies, issues and outlook. Fuel Processing Technology, 71:139-148. Fuel science in the year 2000: Where do we stand and where do we go from here.

[10] Bello H., Joel, O., Ikiensikimema S. S (2012). Improving the efficiency of Fisher Tropsch Synthesis using the $\mathrm{CO}_{2}$ reduction Alternative. SPE paper prepared for presentation at the SPE international technical conference and Exhibition held in Abuja, Nigeria.

[11] Hillestad, M. \&Rafiee A. (2010). Optimal design and operation of a gas-to-liquid process. Chemical Engineering Transactions, 21:1393-1398.

[12] Suehiro Y. et al (2005). A new GTL technology - steam $/ \mathrm{CO}_{2}$ Reforming and the FT synthesis with Novel Catalysts. Paper prepared for presentation at the international petroleum technology conference held in Doha Qatar.

[13] Bybee Karen (2006). Feed-Gas Treatment Design for the Pearl GTL Project., paper prepared for the 2005 International Petroleum Technology Conference, Doha, Qatar. 